ICAMS 2016 $-6^{\text {th }}$ International Conference on Advanced Materials and Systems

\title{
THE EFFECT OF THE FUNCTIONALIZING AGENT TYPE ON PROCESSABILITY, MECHANICAL AND THERMAL PROPERTIES OF POLYPROPYLENE-BASED COMPOSITES
}

\author{
MARIA SÖNMEZ ${ }^{1}$, LAUREN IA ALEXANDRESCU ${ }^{1}$, MIHAI GEORGESCU ${ }^{1}$, MARIA \\ DANIELA STELESCU ${ }^{1}$, MIHAELA (VÎLSAN) NI UIC $\breve{A}^{1}$, DANA GURĂU ${ }^{1}$, ANTON FICAI ${ }^{2}$, \\ DENISA FICAI ${ }^{2}$, IOANA LAVINIA ARDELEAN ${ }^{2}$, OVIDIU OPREA ${ }^{2}$, ROXANA TRUSCA ${ }^{3}$ \\ ${ }^{1}$ INCDTP - Division: Leather and Footwear Research Institute, 93 Ion Minulescu St., Bucharest, \\ Romania,maria.sonmez@icpi.ro \\ ${ }^{2}$ Politehnica University of Bucharest, Faculty of Applied Chemistry and Material Science; 1-7 \\ PolizuSt., Bucharest, Romania, denisaficai@yahoo.ro,anton.ficai@upb.ro \\ ${ }^{3}$ METAV-CD, 31 C.A. Rosetti St., District 2, Bucharest, Romania, truscaroxana@yahoo.com
}

\begin{abstract}
The aim of this study is to monitor the influence of the addition of glass fibers $\left(\mathrm{GF}_{\mathrm{s}}\right)$ treated with polydimethylsiloxane (PDMS) and aminopropyltrimethoxysilane (APTMS) on processability and mechanical and thermal properties of polypropylene. The composites based on PP/GFs were processed on a twin screw extruder-granulator, using $20 \%$ glass fibers, relative to the polymer mixture (PP/PP-g-MA). Composite granules obtained by extrusion were used in order to determine flow indices and the values obtained demonstrate that the addition of $20 \% \mathrm{GF}_{\mathrm{s}}$ does not raise serious processability problems (viscosity of the mixture does not vary very widely). Thermal stability tests under load - HDT demonstrate that the best thermal stability is that of the composite reinforced with $\mathrm{GF}_{\mathrm{s}}-\mathrm{PDMS}$. Mechanical tests also demonstrate that tensile strength, resistance to bending, modulus and elongation at break are superior for the composite reinforced with $\mathrm{PP} / \mathrm{GF}_{\mathrm{s}}-$ PDMS compared with the one reinforced with $\mathrm{GF}_{\mathrm{s}}$-APTMS. This can be attributed to the fact that there is a better compatibility between polydimethylsiloxane-treated fibers and the polypropylene matrix compared with those functionalized with aminopropyltrimethoxysilane. Moreover, glass fibers treated with polydimethylsiloxane are more stable to changes in temperature and pressure that the composite is subjected to during processing. TG-DSC results demonstrate a higher thermal stability of the composite with the addition of functionalized fibers.
\end{abstract}

Keywords: polypropylene, melt flow index, thermal behavior.

\section{INTRODUCTION}

Short glass fibers (GFs) are the most commonly used reinforcing agents in composites based on polypropylene (PP), mainly due to their physical and mechanical properties and the cost price (Biswas et al., 2014; Aguilar et al., 2014). Final properties of composite materials are strongly influenced by the strength and stability of the interphase that develops at the fiber/polymer matrix boundary and by mass ratio between components (Etcheverry and Barbosa, 2012). Adhesion between phases is also affected by aggressive environmental conditions, temperature, humidity as well as final tests that the material will be subjected to during the exploitation process (Ota et al., 2005). Due to the non-polar nature of polypropylene (PP), interaction with inorganic disperse phase is low. Both chemical compounds (functionalization agents) applied to the fiber surface, and coupling agents may be used to improve compatibility. Functionalization agents improve adherence to interface through physical and chemical bonds that develop between components in the system (Zaretsky et al., 2004). Moreover, functionalization agents protect glass fiber surface from aggressive environmental conditions such as humidity and reactive fluids (Sockalingam and Nilakantan, 2012). 
The Effect of the Functionalizing Agent Type on Processability, Mechanical and

Thermal Properties of Polypropylene-based Composites

Organosilanes are considered the most widely used functionalization agents that improve interfacial bonding of glass fibers reinforced composites. Organosilanes' ability to improve adherence depends on several factors such as the nature, type, silane layer thickness, and surface treatment method used for fibers (Broughton et al., 2010; Rausch et al., 2010).

Another commonly used method to improve the glass fiber/polymer interphase is the introduction of a low amount of a polymer modified with specific groups in the thermoplastic matrix (Lin et al., 2015).

Polar groups may be introduced in the polypropylene chains by reactions with species that contain functional groups in their structure, such as ester, carboxylic or anhydride groups (Mäder et al., 1996). This methodology is used in composites based on $\mathrm{PP} / \mathrm{GF}_{\mathrm{s}}$, where small amounts of polypropylene-graft-maleic anhydride (PP-g-MA) is introduced into the mixture, in order to react with the amino group on the surface of the silanized glass fibers (Szentes et al., 2012).

\section{MATERIALS AND METODS}

\section{Materials}

The materials used in this study were the following: polypropylene co-polimer TIPPLEN K 948; polypropylene-graft-maleic anhydride (PP-g-AM), average Mw $\sim 9.200$ by GPC, average Mn 3,900 by GPC, maleic anhydride $8-10$ wt.\%; poly (dimethylsiloxane) (PDMS), grade: analytical standard, vapor pressure: $153 \mathrm{mmHg}$ $\left(20^{\circ} \mathrm{C}\right)$, density: $0.82 \mathrm{~g} / \mathrm{mL}$, molecular weight: 236.53 wt.\%; (3aminopropyl)trimethoxysilane (APTMS): assay: 97\%, refractive index n20/D0: 1.424, density: $1.027 \mathrm{~g} / \mathrm{mL}$, molecular weight: $179.29 \mathrm{wt} . \%$; borosilicatic fiber type E, length $=4.5 \mathrm{~mm}$, diameter $=13 \mathrm{~m}$, alkaline oxide content $>1$.

\section{Method}

Composite materials based on polypropylene reinforced with glass fibres are obtained in two stages:

- In the first stage $-100 \mathrm{~g}$ of glass fibers were added in 1 litre of solution containing ethyl alcohol, distilled water and a percentage of $0.5 \%$ of functionalizing agent (PDMS or APTMS), relative to the amount of glass fibers. The mixture was maintained under continuous stirring for 24 hours, followed by drying in a hot air oven at a temperature of $80^{\circ} \mathrm{C}$ and subsequently at $130^{\circ} \mathrm{C}$ to complete the silanization reaction and evaporation of alcohol.

- The second stage consists in developing the composite on a counter-rotating twin screw extruder granulator as follows: polypropylene powder is introduced in the extruder along with maleic anhydride grafted polypropylene, and glass fibers functionalized with PDMS or APTMS, according to the following 9 zones temperature profile of the extruder: 130-138-161-174-193-189-167- 156$146^{\circ} \mathrm{C}$, with screw rotation speed of $100-300 \mathrm{rpm}$. From composite granules, specimens with the size of $100 \times 10 \times 4 \mathrm{~mm}$ were obtained in a laboratory electric press, with the following processing parameters: Temperature $=175^{\circ} \mathrm{C}$; Pressure $=$ approx. $150 \mathrm{kN}$; Preheating time $=15 \mathrm{~min}$; pressing time $=15 \mathrm{~min}$; Cooling time (at $300 \mathrm{kN}$ pressing) $=12 \mathrm{~min}$. 
ICAMS $2016-6^{\text {th }}$ International Conference on Advanced Materials and Systems

After conditioning at room temperature the specimens were subjected to mechanical and thermal determinations.

Tested formulas based on composites reinforced with glass fiber are presented in Table 1.

Table 1. Formulas of composites based on polypropylene reinforced with treated or untreated glass fibers

\begin{tabular}{lccccccc}
\hline \multicolumn{1}{c}{ Raw materials / Symbol } & MU & PP & P0 & P01 & P1 & P2 & P3 \\
\hline PP K948 & $\%$ & 100 & 97 & 90 & 77 & 77 & 77 \\
PP-g-AM & $\%$ & - & 3 & - & 3 & 3 & 3 \\
PP/GF S untreated & $\%$ & & & 20 & 20 & - & - \\
GF $_{S}$ - PDMS & $\%$ & - & - & - & - & 20 & - \\
GF $_{S}$ - APTES & $\%$ & - & - & - & - & - & 20 \\
\hline
\end{tabular}

\section{Characterization}

Counter-rotating twin screw extruder granulator, TSE 35 type; Electrically heated press, TP 600 with the following characteristics: pump pressure max. 300 bar, pressing surface $400 \times 400 \mathrm{~mm}$, work temperature $150-300^{\circ} \mathrm{C}$ adjustable; HDT thermal stability under load was evaluated using Qualitest HDT1, according to SR EN ISO 75, using $2^{\circ} \mathrm{C} / \mathrm{min}$ heating rate, $0.34 \mathrm{~mm}$ standard deflection at $1.8 \mathrm{MPa}$ flexural stress, in siliconic oil environment; Tensile and flexural (3-point bending) tests were performed using INSTRON 5982 machine, equipped with 10 and $100 \mathrm{kN}$ load cells, on a minimum of 6 specimen per test; Thermal behaviour (DSC-TG) of the samples was determined with the Netzsch 449C STA Jupiter device. Samples were introduced in a closed aluminium crucible and heated at $10 \mathrm{~K} \mathrm{~min}^{-1}$ from room temperature to $200^{\circ} \mathrm{C}$, with dry air flow of $20 \mathrm{~mL} \mathrm{~min}^{-1}$.

\section{RESULTS AND DISCUSSION}

\section{Mechanical Tests}

Table 2 shows the physical-mechanical values obtained for the control sample (PP) and those of composites based on polypropylene reinforced with $20 \%$ glass fibers treated with PDMS or APTMS and untreated.

The hardness of composites does not vary significantly, relative to the reference value $(\mathrm{PP})$ of approximately $6^{\circ} \mathrm{Sh} \mathrm{D}$. Increasing mixture hardness within these (acceptable) limits does not raise serious technological problems during processing.

Flexural strength, Young's modulus and breaking load of the mixtures are significantly improved when using $\mathrm{GF}_{\mathrm{s}}$ functionalized with PDMS (P2) and APTMS (P3), due to bonds that form at the interphase, compared with values obtained for the control sample (PP). This can be attributed to the interactions occurring between amino groups present on the surface of treated $\mathrm{GF}_{\mathrm{s}}$ and anhydride groups of PP-g-AM. In composites reinforced with untreated $\mathrm{GF}_{\mathrm{s}}$ (P01 and P1) values obtained from mechanical determinations are much lower. This is due to reinforcing phase crowding and pores generating in the material, due to evaporation of water molecules on the surface of glass fibers.

Elongation \% is maximum in the case of mixture (P0) due to the addition of $3 \% \mathrm{PP}-$ g-MA. It acts as a plasticizer and reduces the viscosity of the mixture. In the case of 
The Effect of the Functionalizing Agent Type on Processability, Mechanical and Thermal Properties of Polypropylene-based Composites

mixture (P01), elongation value decreases to $1.95 \%$ due to the introduction of $20 \%$, untreated glass fibers which leads to increased viscosity of the mixture. As shown in the case of composites containing both PP-g-AM and $\mathrm{GF}_{\mathrm{s}}-\mathrm{PDMS}$ or $\mathrm{GF}_{\mathrm{s}}$-APTMS (P2 and $\mathrm{P} 3$ ), elongation at break values increase due to a better adhesion between phases. Moreover, depending on the type of functionalizing agent applied to the surface of the fibers, elongation shows maximum values comparable to those of the mixture (P0). This allows the use of high amounts of reinforcing agents without affecting processability.

The density of the tested mixtures increases with the addition of glass fibers.

Table 2. Values of physical-mechanical determinations obtained for control samples and composite materials

\begin{tabular}{lllllll}
\hline \multicolumn{1}{c}{ Determinations/Symbol } & PP & P0 & P01 & P1 & P2 & P3 \\
\hline Hardness ${ }^{\circ}$ Sh D & 66 & 65 & 69 & 70 & 72 & 70 \\
Tear load, N & 50.48 & 51.02 & 53 & 54.71 & 67.42 & 60.94 \\
Resistance to bending, MPa & 33.38 & 33.81 & 33.73 & 34.19 & 40.98 & 38.62 \\
Young's modulus (GPa) & 1.63 & 1.73 & 2.34 & 2.45 & 2.75 & 2.55 \\
Elongation (\%) & 3 & 3.28 & 1.95 & 2.3 & 3.13 & 2.9 \\
${\text { Density, } \mathrm{g} / \mathrm{cm}^{3}}^{3}$ & 0.694 & 0.682 & 1.093 & 1.190 & 1.190 & 1.190 \\
\hline
\end{tabular}

\section{Melt Flow Index (MFI)}

Tests for determining the melt index were carried out at a temperature of $180^{\circ} \mathrm{C}$ using a pressing force of $5 \mathrm{~kg}$.

The MFI results of the six samples are shown in Figure 1 and indicate that with the addition of treated or untreated glass fibers, the MFI value decreases. This can be attributed to the presence of fibers in the melt and their partial alignment, which affect the viscoelastic dynamic of the melt and thus decrease the mobility of molecular chains. However, the flow properties of blends that contain glass fibers are improved significantly by the introduction of coupling agents such as PP-g-MA, and depending on the type of organosilane applied to the surface of the fibers. The best yield, relative to the control sample (PP) is that of mixture ( $\mathrm{PO})$, because the PP-g-MA reduces the degree of crystallinity (molecular weight) of polypropylene. In the case of the mixture (P2, and P3, respectively) containing PDMS or APTMS treated glass fiber and PP-g$\mathrm{MA}$, the flow properties are far superior (71-69.6 g/10min) compared to the mixtures (P01 and P1). This demonstrates that by the appropriate treatment of the glass fibers surface and by introducing PP-g-AM, the viscosity of the mixture is significantly reduced and can be processed easily by injection with high amounts of reinforcing agent without raising serious processability problems and excessive wear of equipment.

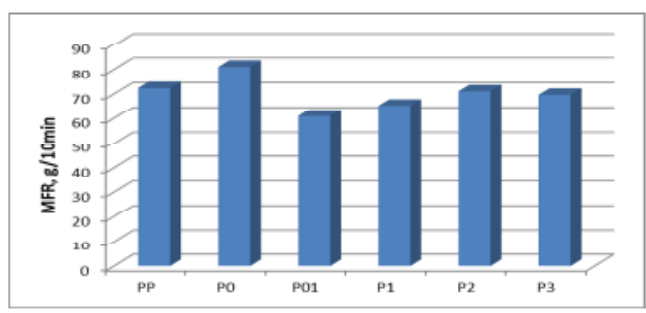

Figure 1. Values of flow index obtained on control samples and $\mathrm{PP} / \mathrm{GF}_{\mathrm{s}}$ treated and untreated composite samples 
ICAMS $2016-6^{\text {th }}$ International Conference on Advanced Materials and Systems

\section{Thermal Stability under Mechanical Loading - HDT}

Softening or deflection temperature determinations (HDT) of blends based on polypropylene reinforced with treated and untreated glass fibers were performed in compliance with SR EN ISO 75, and the resulting values are presented in table 3.

The analysis shows that the thermal stability of the blends reinforced with untreated glass fibers (P01), $\mathrm{GF}_{\mathrm{s}}$-PDMS (P2) or $\mathrm{GF}_{\mathrm{s}}$-APTMS (P3) improve the thermal stability of the composites compared with the control sample (PP) by about $60^{\circ} \mathrm{C}$. This can be attributed to the fact that by adding glass fibers thermal stability improves and flammability of the products reduces. However, the best thermal stability is that of P2 blend, due to the presence of Si-O-Si group in the PDMS main chain, which gives an excellent temperature stability.

Table 3. Values of HDT deflection temperature obtained on control samples and PP/GF composite samples

\begin{tabular}{ll}
\hline Symbol & Temp $\left[{ }^{\circ} \mathrm{C}\right]$ \\
\hline PP $(\mathrm{K} 948)\left(175^{\circ} \mathrm{C}\right)$ & 64,9 \\
P0 $\left(175^{\circ} \mathrm{C}\right)$ & 71,1 \\
P01 $\left(175^{\circ} \mathrm{C}\right)$ & 80 \\
P1 $\left(170^{\circ} \mathrm{C}\right)$ & 95,3 \\
P2 $\left(170^{\circ} \mathrm{C}\right)$ & 125,5 \\
P3 $\left(170{ }^{\circ} \mathrm{C}\right)$ & 109,6 \\
\hline
\end{tabular}

\section{Complex Thermal Analyses}

The thermal analyses of the four samples reveal important differences from both thermal behavior and mass changes in the range of 30 to $900^{\circ} \mathrm{C}$. From the point of view of the thermal behavior we can observe that the melting point of the four samples is in the 170 and $180^{\circ} \mathrm{C}$.

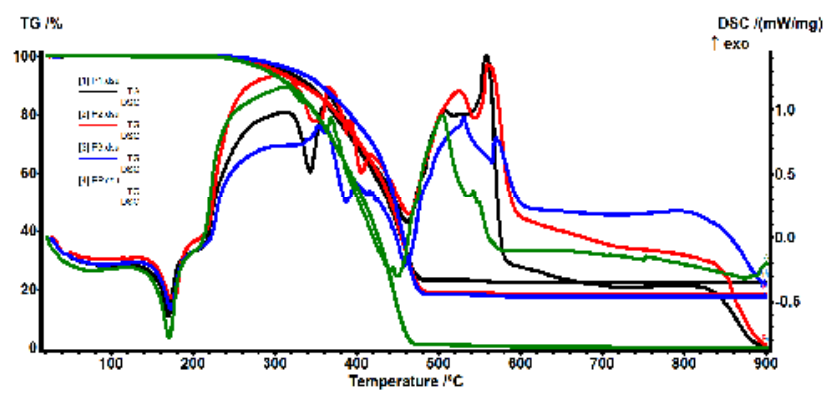

Figure 2. DSC-TG curves recorded on control samples and PP/PP-g-AM/GFs composite samples

The use of the functionalized glass fibers lead to an increasing stability of the samples, the melting point increasing while, the use of bare glass fibers lead to a decrease of the stability proved by the decreasing of the melting point. The very good compatibility between PP and $\mathrm{GF}_{\mathrm{s}}-\mathrm{PDMS}$ can be highlighted by the splitting of this peak into two peaks (centered at 172.0 and $178.0^{\circ} \mathrm{C}$ ). All the three composite samples are completely burned at $\sim 600^{\circ} \mathrm{C}$, the last strong burning effect being centered at 558.4; 
560.2 and $570.3^{\circ} \mathrm{C}$ while the bare PP exhibit this effect at $550^{\circ} \mathrm{C}$. The mass loss was analyzed and based on these data it can conclude that P2 and P3 lost 4.19 and respectively $4.90 \%$ comparing to $\mathrm{P} 1$ which means that the degree of functionalization of $\mathrm{GF}_{\mathrm{s}}$ was $\sim 22 \%$ in both cases.

\section{CONCLUSIONS}

The results obtained from mechanical determinations show that the addition of small amounts of coupling agent (PP-g-MA) and surface treatment of fibers with organosilanes, especially PDMS, considerably improve adherence to interphase through amino and anhydride groups. The flow properties of blends are strongly influenced by the type of treatment applied to the surface of the fibers and the presence of a coupling agent because they influence the viscosity of the mixture, in a positive sense. Thermal stability, HDT, shows significantly higher values compared with the control sample (PP), in composites containing glass fibers, especially in the case of blends containing PDMS modified glass fibers.

\section{Acknowledgements}

This work was financially supported by MENCS - UEFISCDI, in the frame of Romanian PN II - Partenerships - Joint Applied Research Projects Programme contract No. 168/2012.

\section{REFERENCES}

Aguilar, H., Yazdani-Pedram, M., Toro, P., Guijada, R., Angel, M. and Manchado, L. (2014), "Synergic effect of two inorganic fillers on the mechanical and thermal properties of hybrid polypropylene composites", Journal of the Chilean Chemical Society, 59(2), 2468-2473.

Biswas, A.K., Cherif, C., Hund, R.D., Shayed, M.A. and Hossain, M. (2014), "Influence of coatings on tensile properties of glass fiber", Materials Science, 20(1), 50-54.

Broughton, W.R., Lodeiro, M.J. and Pilkington, G.D. (2010), "Influence of coupling agents on material behaviour of glass flake reinforced polypropylene", Composites Part A Applied Science and Manufacturing, 41, 506-514.

Etcheverry, M. and Barbosa, E.S. (2012), "Glass fiber reinforced polypropylene mechanical properties enhancement by adhesion improvement", Materials, 5, 1084-1113.

Lin, J.H., Huang, C., Liu, C.F., Chen, C.K., Lin, Z.I. and Lou, C.W. (2015), "Polypropylene/short glass fibers composites: Effects of coupling agents on mechanical properties, thermal behaviors, and morphology", Materials, 8, 8279-8291.

Mäder, E., Jacobasch, H.-J., Grundke, K. and Gietzelt, T. (1996), "Influence of an optimized interphase on the properties of polypropylene/glass fibre composites", Composites Part A Applied Science and Manufacturing, 27, 907-912.

Ota, W.N.; Amico, S.C.; Satyanarayana, K.G. (2005), "Studies on the combined effect of injection temperature and fiber content on the properties of polypropylene-glass fiber composites", Composites Science and Technology, 65, 873-881.

Rausch, J., Zhuang, R.C. and Mäder, E. (2010), "Systematically varied interfaces of continuously reinforced glass fibre/polypropylene composites: Comparative evaluation of relevant interfacial aspects", eXPRESS Polymer Letters, 4(9), 576-588.

Sockalingam, S. and Nilakantan, G. (2012), "Fiber-matrix interface characterization through the microbond test", International Journal of Aeronautical and Space Sciences, 13(3), 282-295.

Szentes, A., Varga, Cs., Horváth, G., Bartha, L., Kónya, Z., Haspel, H., Szél, J. and Kukovecz, Á. (2012), "Electrical resistivity and thermal properties of compatibilized multi-walled carbon nanotube/polypropylene composites", eXPRESS Polymer Letters, 6(6), 494-502.

Zaretsky, E., Botton, G.D. and Perl, M. (2004), "The response of glass fibers reinforced epoxy composite to an impact loading", International Journal of Solids and Structures, 41, 569 - 584. 